\title{
From nurse to patient: A journey to healing
}

\author{
Leo Begazo \\ Oncology Nursing Society; Clinic Operations Manager, Moffitt Cancer Center, Tampa, FL, USA
}

\begin{abstract}
The nurse manager of an oncology clinic in a major cancer center shares his personal experience as a COVID-19 patient with other health care workers. He has spent two weeks in intensive care and found himself on the brink of death. In a lively description, he underlines the aspect of care that contributed to his cure. This included the respect that his caregivers expressed to his values, his love of his family and his religious beliefs. The communication of the caregivers was always honest and compassionate. He learned that love is the strongest motivation to survive in the course of a life-threatening disease and that healing is possible even in the absence of cure.
\end{abstract}

\section{Introduction}

A previously healthy nurse manager of an outpatient oncology clinic was infected by coronavirus and spent two weeks in intensive care, on the brink of death. This paper shares the insights he has developed from this experience. With his narrative he plans to provide a lively documentation of patient and provider interactions in the course of a life-threatening illness.

The management of death is integral part of nursing training. ${ }^{1-3}$ For patients with metastatic cancer death is still a common outcome and the oncology nurse learns how to prepare to death a patient and his/her loved ones, how to talk about death, and how to recognize and face the reactions of a person informed that his/her life will soon end. ${ }^{4}$ The author's history highlights practical aspects of this training that make the relation effective and rewarding.

The trajectory of dying originally described by Kubler Ross $^{5}$ for patients with chronic diseases may not apply in the course of an acute illness, as fear of the unknown, con-

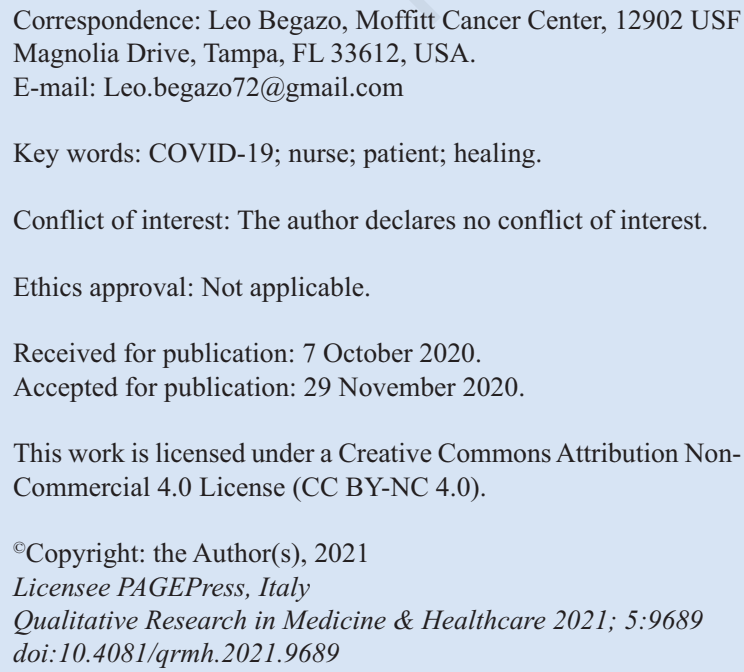

cern for the loved ones and regret for projects left unfinished may overwhelm all coping mechanisms. The author found comforting the respect of his dignity, the honest and compassionate update of his condition, the constant effort to keep him touch with his family despite infectious isolation, and the acceptance of his request to pray with him by the ICU nurses.

The lasting lesson he derived from his experience is that healing is possible even when cure is not reachable and it should represent the final goal of every medical intervention.

\section{Case Report}

April $5^{\text {th }} 2020$ will remain a landmark in my personal history. Ten minutes after my wife placed the call the ambulance arrived. My O2 saturation was $87 \%$, barely compatible with life. The paramedics wasted no time: after putting a breathing mask on my face and an intravenous solution in my arm vein, they loaded me on the stretcher and we left for the closest hospital. True, we were still waiting the results of the test after almost three weeks since the initial symptoms, but there was no question I had a rampant COVID-19 infection.

As the ambulance was clearing its way with the howls of the siren, I felt overwhelmed by a number of different emotions. No words can describe what I felt. Everything had happened so quickly that I had no time to adapt to the situation. Also I had a blistering headache that impeded organized thoughts and my temperature had been $103 \mathrm{~F}$ the whole day despite heavy doses of acetaminophen.

My preponderant emotions were uncertainty and fear. I had an incurable disease with an unpredictable course. I might have died. I might have died without saying goodbye to my family and friends in Tampa and around the world. I might have died without seeing the graduation of my children from college; without getting my Master degree in nursing, without being able to spend my retirement with my beloved wife enjoying our lives together. 
I had been a nurse 26 years and I worked in emergency room and intensive care before becoming a manager of an oncology clinic in a major cancer center. Quite often my work had involved rapid decision making in the care of multiple patients and in every circumstance I felt I had the situation under control. I prided myself for being a good leader. For the first time now I had no control of the situation and could not trust that anybody else would be able to take control of this mysterious virus. And what about my family? They had been exposed daily to my cough, to my breaths, to my touch. Will they also develop the infection? My wife is my same age. Will she survive? And who will take care of them if I die? And of my two children if we both succumb to the disease?

Before coming to the USA, I had been already a nurse in the Peruvian Air Force where I treated wounded soldiers as result of them fighting rebels in the Amazonian jungle. Yes, there too I might have died. But it was different. I had procedures to follow, to help save their lives after fighting an enemy that was known. COVID-19 instead was an unknown enemy. We just knew that the risk of death increased with the patient age and the presence of comorbid conditions. Though I was healthy enough I was overweight and that was a risk factor too.

The other recurrent emotion related to the "what if" question. What could have I done different? On March $18^{\text {th }}$ I woke up coughing, hot to touch and with a general feeling of malaise. Those were the symptoms of flu. Maybe flu was coming a little earlier this year as a consequence of the COVID-19 pandemic. My family doctor seemed to agree. Still he found advisable to order a COVID-19 test. Fever and cough persisted for a week and I was becoming every day more fatigued. I could hardly get up from bed. My wife drove me to the emergency room and I was diagnosed with pneumonia and prescribed multiple antibiotics including ciprofloxacin and azithromycin, bed rest and plenty of fluids. Even the ER doctor hinted that I might have contracted coronavirus and recommended to come back if symptoms had worsened. He did not feel appropriate to admit me to the hospital however, because my condition was stable and the hospitalization might have increased my risk of infection if I was not already infected as well as the risk of transmission to other patients if I were infected.

Things turned from bad to worse. After three days I became unable to leave the bed and unable to breath. And now I am on my way toward a very uncertain outcome in a rushing ambulance asking for the right of way. Three days later the test confirmed the coronavirus infection when everybody was all but certain of it.

Should I have paid more attention to the initial symptoms? Notoriously doctors and nurses ignore symptoms of serious diseases until it is too late. Paradoxically, it is our very medical knowledge that allows us to consider alternative, more benign diagnoses. I had met a colleague who delayed by two months the biopsy of a cervical lym- phoma as she was convinced to have just a sore throat. I met a doctor who barely made it to the hospital after fainting. His hemoglobin was $5 \mathrm{GM} / \mathrm{DL}$ and he was actively bleeding from three gastric ulcers. For three months. He had simply ignored his melena! Have my doctor and the ER doctor been too cavalier? Though I had followed very carefully all the recommendations of the CDC and of our hospital infection management office I could not help asking myself if I had avoided to maintain all possible precautions when rushed to heed the multiple crisis of a very busy clinic. This carelessness would have been unforgivable in our center where we have been provided with PPE (Personal Protection Equipment) since the very beginning of the pandemic. Questions without an answer. I would have almost preferred to have some mistake to acknowledge, to be able to explain my disease, rather than accepting to be a victim of chance-or of an act of God.

The anguish not to have time overwhelmed me. Time for what? One may ask. Time for a lot of things I tell you. Having been raised in an overwhelming catholic country I had been advised to repent of all my sins and plead to be forgiven before facing my creator. But tottering on the ambulance gurney, deafened by the howls of the siren, heated up by fever, punished by unrelenting headache, I could not possibly remember a single sin to be forgiven of. As an oncology nurse I gained some expertise in ministering to dying patients. A successful approach invites patients to distillate from their personal histories the most meaningful moments and to prepare an essence to share with their loved ones. Somehow this preparation will allow them to defeat death by coopting death in their living experience and making of it one of the most precious moments of their lives. But who had time to think of any meaningful moment in my situation?

In retrospective I was surprised for not having felt angry. We have been told that anger is the first response to the diagnosis of any lethal disease such as cancer. ${ }^{5}$ But I did not have time to brew any anger. I felt like a survivor of a crash being rushed to the hospital and hoping to make it in time. Anger may be a spontaneous response to a diagnose of incurable cancer, when the patient learns that he/she is going to die, but still has a few months to live, not for somebody who may have just hours to live.

We stopped at a small hospital, not the major hospital where I had asked to be carried. I guess the paramedics felt it was not safe to wait that long, or maybe the major hospital was full. "Oh my God, I told myself, I know now I am going to die!" As a health professional I know the outcome of care is related to the experience of the caregiver. The more the health professionals are experienced, the better are the chances to get well. Fortunately, my assumptions in this case were wrong.

After three hours in the ER I was admitted to the Patient Under Investigation (PUI) Unit where you find patients who need diagnostic tests and are too unstable to remain home. I was very pleased by the empathy shown 
by the nurses and the doctors. The nurse who interviewed me on admission referred to me as Mister Begazo, asked whether I preferred to speak English or Spanish, and before beginning to pose her protocol questions asked about my profession and my family. Both doctors and nurses acknowledged my profession as nurse manager. The doctor talked to me as to a colleague and the nurses during the morning visits asked my recommendations about some problems they had encountered during the day. I remember to have read somewhere that the Roman Emperor Adrian stated "It is difficult to remain emperor in front of a physician" that I may translate "It is hard to remain a health professional in front of a health professional." Indeed, it is hard to remain oneself in the medical world, when they ask you to dismiss your personal cloths and to wear the same gown of everybody else as if it were a uniform, when your movements are restricted like those of a prisoner in jail. I remember that one of the doctors I worked with, when he had a patient who was a minister always asked him/her to say a prayer at the end of the visit. He explained me that he wanted every patient to maintain his/her dignity during the visit, show to him/her that we were interested in a person, not just in his/her cancer. They asked every day of my family and they asked my nursing advise: they did honor my dearest assets, my family and my work. They did not miss a chance to remind me that I was a person with coronavirus, not a case of coronavirus.

Things kept going from bad to worse. After two days my lungs were replenished with coronavirus. My nurse activated the call for an intensive care unit consultation and in less than 20 minutes I was attached to the all possible monitors in intensive care. I felt like a fly trapped in a spiderweb. At this point sadness prevailed over fear. Sadness because I might have not met my family again; sadness for being unable to kiss my wonderful wife and tell her how much I loved her one more time and to thank her one more time for her love, sadness for what I left undone and I would have not been able to accomplish, sadness for having to die before I was ready for it, sadness for dying alone. As a nurse, I witnessed hundreds of deaths. I remember rooms filled with children and grandchildren while a patriarch or a matriarch were receiving the last rites, and I relished their tears as the quintessence of ultimate consolation. In a few cases I saw disheveled patients dying alone and I had felt desolation rather than compassion. They lacked the consolation of tears. And now I was going to die like that woman whose name and age we never found out, brought into my ward with massive ascites while in hepatic coma.

But my family was present, as I had become real close to the hospital personnel. They did not miss a single time to encourage me with a smile and adding :"Leo you got it," "Leo keep fighting! Your family is with you." And they facilitated the contacts with my family through phone calls. They even showed me a video that my wife and chil- dren had prepared to tell me they were trusting in my recovery and they were looking forward to welcoming me home again. About my family: as I was in the ICU my wife was admitted to the same hospital, few rooms away, with coronavirus. Despite she was also in ICU, she did not have the severity of my case. And while I was worried for her I also felt in my depth that her disease was an ultimate act of love, that she wanted to partake my suffering. As a Christian I saw in her Christ who had elected to partake the suffering of our wretched humanity.

And here it came, the moment of the truth. It is the moment that every health professional fears because we are overwhelmed by the awesome responsibility to guide the patient into a territory that is largely unknown to us. We have to lead them to the threshold of death and we really don't know what death is nor do we know which obstacles on the road we will have to overcome. We have to play God without the wisdom of God and sometimes even without faith in a divinity. Based on the information we provide the patient will have to make heartbreaking decisions, that may turn out to be the wrong decisions. And this time I was the patient, and as a health professional I knew that the message I would have received was based on poorly known facts. I did trust completely my caregivers but unlike other patients I happened to know all the uncertainties they were dutybound to cover.

Early in the morning, the glass door of my ICU room opened and I saw my doctor and two nurses ready to talk to me. I felt my heart stop for a second. Just by the way they were looking at me I learned that bad news was coming my way. Suddenly Dr. Y started talking: "Hi Leo, I am sorry but I don't have good news for you. Leo, your lungs are taken by the virus and if we don't put you on the vent now, most likely you will die on this bed in the next twenty-four to forty-eight hours." Instead of fear my first reaction was a discomforting realization. No matter our status in life, our education, our degree or our wealth, we are vulnerable like any other person and there is nothing you can do to buy life. I had no way to try to bribe biology and science in order of acquiring a new life. After his announcement, I asked Dr Y to be allowed a phone call to my wife. A few rooms away and yet as unreachable as if she were on Mars, my spouse mentioned that Dr. Y had already spoken with her and disclosed to her the severity of my illness. She had provided the consent to mechanical ventilation. I finished my conversation by telling her, “If I don't wake up, remember that I love you and please tell our children that I love them with all my heart." She answered "I love you too honey, and I don't want you to die! Do fight this virus with all your strength because we need you". After I hung up the phone, I told Dr. Y I needed a minute to pray before engaging in the next step of my care that was going to include medical induced coma. Two nurses, one on each side of my bed, held my hands supporting me in this brief visit of eternity. I prayed and told the Lord that I trusted Him and I trusted 
my life to Him. I felt at peace and I knew I was ready to accept the final outcome even if it involved death. It is just you, God on the other side of death.

At that time a clinical trial with the drug tocilizumab became available and my wife eagerly consented to my participation to the trial! Thanks to her insight five days later I was ready for being extubated and eight days later for discharge from the hospital. And now I am on my way to recovery and keen as ever to go back to my nursing and to share with my patients the lessons I learned at the South Bay Hospital of Sun City.

\section{Discussion and conclusions}

Some people may make fun of me if I say that I was miraculously healed and may warn me to thank the developments of science rather than a questionable divinity that escapes our senses. No use to argue. Nobody can dissuade my conviction that all human events, including clinical research, are acts of God and the ventilator, and the empathetic hospital personnel and the new drugs were gifts of God.

But even the most skeptical and agnostic person cannot deny a fact. It was the care of my caregivers and my family that led me to my cure. I know that without the care of my nurses and my doctor and the love of my family I would have probably surrendered my life before getting to the ventilator, before being able to be healed with tocilizumab! Science may be essential, but certainly it is not sufficient to cure a life-threatening disease. The motivation to live enables us to utilize science to save our lives. The motivation to live is reinforced by love, to know somebody for whom every effort to live becomes worthy. Even during my medical induced coma, I heard voices telling me not to give up for the sake of the people who loved me.

From my ordeal, I learned two important lessons that will inform my practice from now on.

Empathy and compassion facilitate the delivery of care and the achievement of a cure. I will not be shy in expressing my care to my patients nor will I be shy in encouraging the patient's loved ones to express their love in every possible occasion. I will share with them how the unrelenting love of my spouse, and the demeanor of my caregivers, motivated me to live even during the darkest times of my disease.

Empathy and compassion also facilitate healing, and while in many case a cure may not be achievable, healing is always achievable. I understood this concept fully when I prayed with the nurses prior to medically induced coma. At that time I was not anymore fearful to die. I was at peace with myself. Cure refers to the disease, healing refers to the ability of the person to come to terms with the disease even when the outcome is death. Nobody can avoid death. If death is the ultimate enemy the whole humanity is doomed as all of us are going to die. The only way to defeat death is to face death as a most meaningful time of our life. For some people, including myself, religious faith represents a way to healing. As any health professional who uses every available instruments to help the patients I will not shy from praying with my patients if they ask me to do that. Whether or not my prayer led to the clinical trial with tocilizumab, my prayer healed me even before I was intubated. The prayer pervaded me with trust.

I am left with a challenge that may appear unsurmountable: how to inspire empathy and compassion to my staff, and I mean not only the nursing staff but everybody working in the clinics I work in partnership. Because I realize that empathy and compassion represent a communal goal. Clearly, you cannot teach compassion and empathy in a classroom. But kindness and even-tempered behavior may create an atmosphere favorable to the germination of compassion. After all, people who are treated with respect are more likely to show respect of other people. The main reason people fail to acknowledge another person's dignity is because nobody might have acknowledged their own worthiness.

"A single death is a tragedy; a million death is statistics" stated Joseph Stalin to justify his vain attempt to build a proletarian government over millions of death. Sadly, this cynical assumption might have been adopted by modern medicine. Coronavirus caused already more than a million deaths in the world and we have learned to live with it. Health professionals may be so overwhelmed to have become unable to see the single patient. Emergency rooms have become field hospitals where one needs to make the painful choice to care only for the patient most likely to survive. Even before the epidemics however, overspecialization and widespread adoption of technology, including the electronic health records, have progressively eroded the relation of practitioner and patient. I am proud to say that the most important mission of the nursing profession is to keep alive this relationship, to prevent that a single death disappeared anonymously in the statistic ocean. Unlike the Emperor Adrian I felt an emperor at south Bay hospital and I plan that every patient under my care feels an emperor!

\section{References}

1. Castellà-Creus M, Delgado-Hito P, Casanovas-Cuellar C, et al. Barriers and facilitators involved in standardised care plan individualisation process in acute hospitalisation wards: A grounded theory approach. J Clin Nurs 2019;28:4606-20.

2. Schreiner L, Wolf Bordonaro GP. Using Nontraditional Curricular Tools to Address Death and Dying in Nurse Education. J Hosp Palliat Nurs 2019;21:229-36

3. Clark R. Letting Go: The Role of the Nurse During Death and Dying. J Gerontol Nurs 2019;45:2-3.

4. Paterson C, Gobel B, Gosselin T, et al. Oncology Nursing During a Pandemic: Critical Reflections in the Context of COVID-19. Semin Oncol Nurs 2020;36:151028.

5. Kübler-Ross E, Wessler S, Avioli LV. On death and dying. JAMA 1972;221:174-9. 